\title{
Correction to: The Clinical Spectrum of Fibromyalgia and Its Treatment: An Overview
}

\author{
Jacob N. Ablin
}
Correction to: Chapter 11 in: J. N. Ablin, Y. Shoenfeld (eds.), Fibromyalgia Syndrome, https://doi.org/10.1007/978-3-030-78638-0_11

The original version of this chapter was inadvertently published without the coauthor name. The chapter and book front matter has been corrected to include the co-author name, Shai Shtrozberg. 